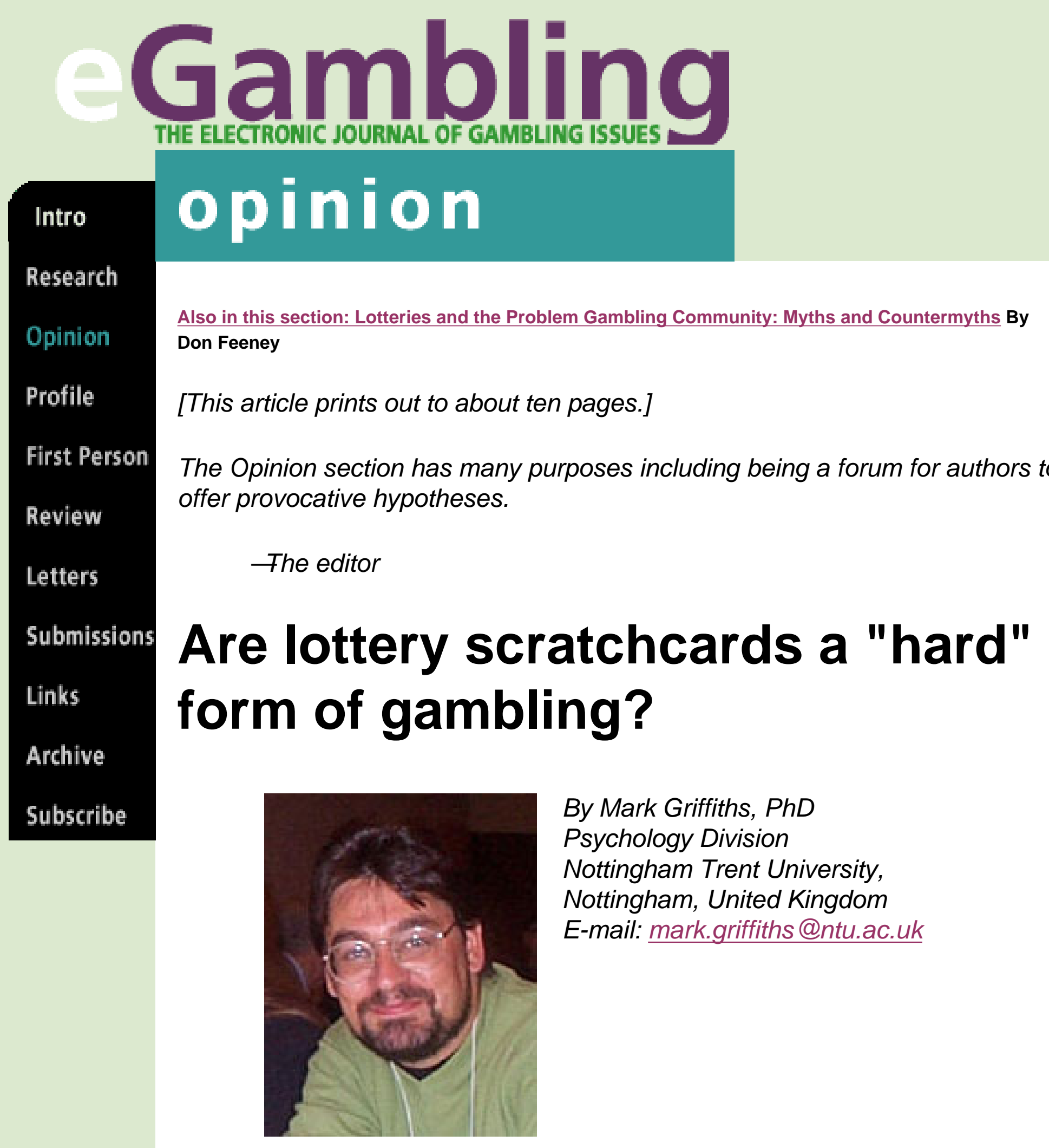

\title{
Abstract
}

This article argues that scratchcards are not an extension of the online U.K. National Lottery but an entirely different form of gambling, with its own 
implications for future gambling policy. It also argues that scratchcards are potentially addictive and should be considered a "hard" form of gambling. The author suggests that scratchcard gambling could become a repetitive habit for some people because of their integrated mix of conditioning effects, rapid event frequency, short payout intervals and psychological rewards coupled with the fact that scratchcards require no skill and are highly accessible, deceptively inexpensive and available in "respectable" outlets.

On March 21, 1995, Camelot the consortium that runs the U.K. National Lottery online -introduced scratchcards. Like the online game, $28 \%$ of ticket sales contribute towards "good causes" distributed by the National Lotteries Charities Board. Although scratchcards are not new to the United Kingdom, many people view them as intricately linked with the National Lottery.

Camelot's scratchcards were the first to benefit from both heavy advertising (television, national newspapers, billboards, etc.) and large jackpots (e.g., $£ 50,000$ ), which meant they became successful very quickly.

\section{Scratchcards: Some frequently asked questions and answers}

Before going into more detail, here is a brief overview of scratchcards in a "frequently asked questions" model used by Aasved and Schaefer (1995) in their account of pull-tab gambling.

\section{What are scratchcards?}

Scratchcards are laminated cardboard tickets where the object is to win money by matching three symbols or amounts of money by rubbing a box covering the symbols or amounts. The face of every scratchcard contains the name of the game (e.g., Mystic Money), the operator's name and the objective (e.g., "Match 3 symbols to win amounts shown."). The reverse side of the scratchcard usually contains the simple play instructions (i.e., "Rub off the box. Find 3 like amounts, win that amount"), overall odds of winning (which differ in most games but are usually about one in five), the prize range (e.g., $£ 1$ to $£ 50,000$ ), the operator's address to claim big prizes (usually over £75) and a notice that "Players must be 16 years or older."

Where are they found?

Scratchcards are sold in a wide variety of outlets, including supermarkets, news agents, petrol stations, post offices, small retailers, 
etc.

How is the game set up?

There are numerous different scratchcards with a wide assortment of payout structures, prizes and profit margins. Typical games have top prizes ranging from $£ 10,000$ to $£ 1$ million (but commonly $£ 50,000$ ).

How is the game played?

All the ticket buyer must do is rub off the box's coating in an attempt to find matches of three symbols or amounts (see figures 1 to 4). Most scratchcards cost $£ 1$ to play. Games have many small winning tickets (minimum prizes of $£ 1$ or $£ 2$ ) but very few big winning tickets.

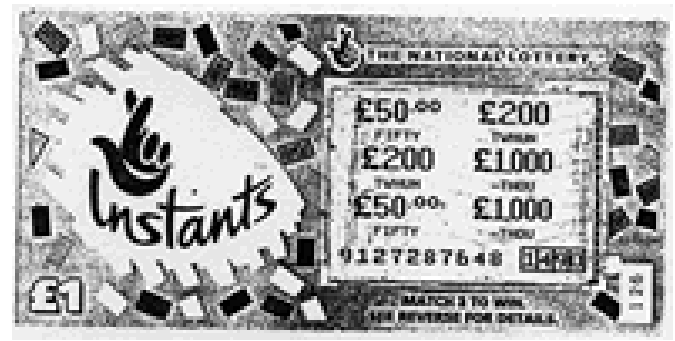

Figure 1 (click images to enlarge)

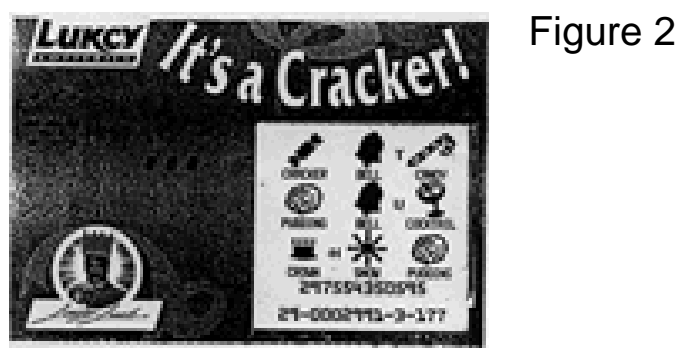

Figure 3

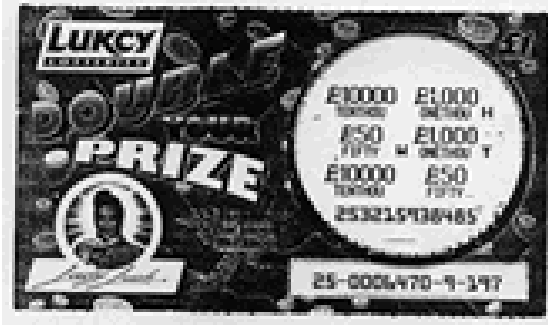

Figure 4

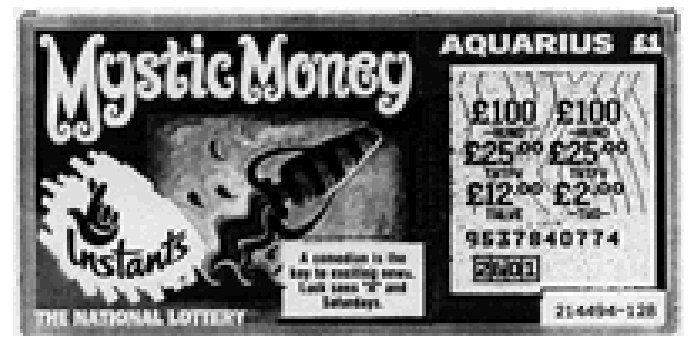

Where does the money go?

Although there are a number of independent scratchcard operators, 
Camelot's scratchcards have over $90 \%$ of the available U.K. market (Creigh-Tyte, 1997). Therefore in the case of most scratchcards, $28 \%$ goes to "good causes," $12 \%$ in taxes to the U.K. Treasury, $50 \%$ is returned in prizes, $5 \%$ goes to operating costs and profit and $5 \%$ represents the retailer's commission.

The rest of this paper examines the psychological aspects of "lottery" scratchcards. At this point, it is worth noting a trend for associating the word "lottery" with other forms of gambling to make these activities seem innocuous (e.g., video lottery terminals). However, this paper argues that scratchcards are not an extension of the U.K. National Lottery online game but an entirely different form of gambling, with its own implications for future gambling policy. Moreover, scratchcards are potentially addictive and should be considered a "hard" form of gambling.

\section{Scratchcards -A potentially addictive game?}

A previous report by the Royal Commission (1978) noted that casino-type gambling activities came closest to incorporating the largest number of gambling-inducing characteristics. The characteristics outlined include a high payout ratio (i.e., small bets and large jackpots) and rapid betting or "event frequency." In addition, heavy losses were viewed as a likely occurrence because this type of gambling contains characteristics that allow continuous gambling. These three features are also present in scratchcards, and have been described by Griffiths (1995b; 1995c) as "paper fruit machines." Some operators even use the fruit machine (and other forms of gambling) in their product's basic design (see Figure 5).

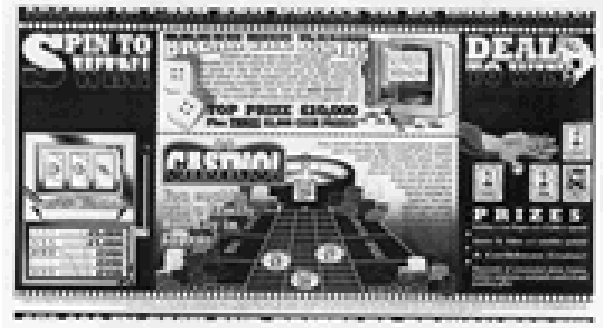

Figure 5. (click to enlarge)

Further to this, a number of papers written from a psychological perspective describe how and why scratchcards may be potentially addictive (e.g., Griffiths, 1995b; 1997). Like fruit machines, scratchcards have a short payout interval (i.e., only a few second's interval separates the initial gamble and the winning payment) and rapid event frequency (i.e., the time gap between each individual gamble is very short if people engage in continuous play). This 
means that the loss period is brief with little time given over to financial considerations, and more importantly, winnings can be used to gamble again almost immediately.

A number of other factors are linked with these characteristics. The first of these concerns the frequency of opportunities to gamble. Logistically, some gambling activities (e.g., the U.K. National Lottery, football pools) have small event frequencies (i.e., there are only one or two draws a week) making them 'soft' forms of gambling. However, in the case of scratchcards there are few constraints on repeated gambling as limits are set only by how fast a person can scratch off the covering of the winning or losing symbols.

The frequency of playing when linked with two other factors -the result of the gamble (win or loss) and the actual time until winnings are received -exploit certain psychological principles of learning. This operant conditioning process conditions habits by rewarding people for specific behaviour. Reinforcement occurs through presentation of rewards such as money. To produce high rates of response, schedules that present rewards intermittently are most effective (Skinner, 1953; Moran, 1987). Since scratchcards operate on such schedules, it is not surprising that high rates of response (i.e., excessive gambling) can occur. Promoters appear to acknowledge the need to pay out winnings as quickly as possible, which indicates the gambling industry views that receiving winnings acts as an extrinsic reward for winners to continue gambling.

Another related aspect to operant conditioning is the "psychology of the near miss" which can act as an intermediate reinforcer. Near misses are failures that came close to being successful. A number of psychologists (Reid, 1986; Griffiths, 1991; 1999) have noted that near misses appear to encourage future play -inducing continued gambling - and that some commercial gambling activities, particularly fruit machines and scratchcards, are formulated to ensure a higher than chance frequency of near misses. The potential danger of the near miss element of scratchcards was first documented in the 1970s: scratchcards were termed "heartstoppers" because they gave the illusion of coming close to a big prize (Moran, 1979).

Heartstoppers have never been adequately defined, and in Moran's original formulation appear to include simple near miss designs (two winning symbols when three are needed) like the scratchcards in Figures 1 and 2 (above). This author would define heartstoppers as those instances where there are two winning symbols and a third one that looks similar to the other symbols. For instance, in Figure 3, the "£1000" and "£10000" amounts look very similar and for a split second a person may think they have genuinely won something. Another ploy that scratchcard designers use is having three near misses on 
one scratchcard (e.g., Figure 1) so that it does not matter in what order the person scratches off the box, there will always be a chance that the very last panel they scratch off could be the winning one.

\section{Adolescent scratchcard gambling}

One of the main objectives of gaming regulation, which is common to all effective systems of gaming regulation in democratic jurisdictions, is protection for children and vulnerable persons (Littler, 1996). However, with scratchcards, a concern is the ease with which adolescents can buy them. Some supermarkets, petrol stations, conveniences stores and news agents have broken the law by selling scratchcards to children as young as 11 and 12 (Garner, 1995; MacDonald, 1995; Moran, 1995). In addition to this, advertising for both the U.K. National Lottery and scratchcards is fast persuading viewers that gambling is normal. Children are thus being further saturated with the principles of gambling and are perhaps growing up to believe gambling is socially acceptable.

Many studies (see Griffiths, 1995a, for an overview) have shown that fruit machine gambling amongst adolescents is a popular activity in the United Kingdom. Although most adolescents control their gambling activity, a minority of adolescents who gamble have gambling behaviour that is pathological. Accepting that fruit machine gambling is a major problem for a minority of adolescents, some adolescents may find scratchcards equally addictive, which seems to be the case according to recent evidence. For example, two studies in the United Kingdom (Griffiths, 2000; Wood \& Griffiths, 1998), reported that approximately $5 \%$ of adolescents aged 11 to 16 were "addicted" to scratchcards based on DSM-IV criteria.

\section{Some conclusions}

At the very least, the characteristics of scratchcards have the potential to induce excessive gambling regardless of the gambler's personality, environment or genetic make-up. These characteristics include the capability to produce psychologically rewarding experiences in financially losing situations - particularly the psychology of the near miss. Therefore, it can be argued that scratchcards are a "hard" form of gambling. At present, the Home Office has a crude distinction between "hard" and "soft" forms of gambling. Their most recent definition is outlined here: 
"Hard gambling is a colloquialism for those forms of gambling which are considered to carry greater potential risks than others, usually because of the high or rapid staking associated with them" [author's emphasis] (Home Office, 1996; p. 3).

From this definition and the preceding discussion, conclusion is that "soft" gambling refers to activities, such as the U.K. National Lottery and football pools, and "hard" gambling includes roulette, blackjack, fruit machines, horse and greyhound race betting and instant scratchcards.

It is not hard to see how scratchcard gambling could become a repetitive habit between its integrated mix of conditioning effects, rapid event frequency, short payout intervals and psychological rewards and the fact that scratchcards require no skill and are deceptively inexpensive, highly accessible and sold in "respectable" outlets. Although the perceived element of skill in gambling has been argued to be an important component in the development of some gambling addictions (e.g., Griffiths, 1994; 1995b) it is not necessarily critical. There is plenty of evidence (e.g., Langer, 1975; Wagenaar, 1988) to suggest that a gambler's ignorance about probability or situational cues may encourage gamblers to think they have some influence over mainly chancedetermined activities. However, it is difficult to use such information directly in regulation of these activities.

Another complicating factor is the risk that educating the public about gambling may have the reverse of the desired effect and actually increase awareness, and thus, participation. It may be that regulation is best achieved not through changing the structural characteristics but through practices such as prohibition of advertising, decreasing the number of outlets available for gambling and geographically locating gambling establishments away from sites where more vulnerable members of the population are found, such as schools.

\section{References}

Aasved, M.J. \& Schaefer, J.M. (1995).

"Minnesota slots": An observational study of pull tab gambling. Journal of Gambling Studies, 11, 311-341.

\section{Camelot (1995).}

The National Lottery 1st Anniversary Press Pack. Author. 


\section{Creigh-Tyte, S. (1997, June).}

The U.K. National Lottery and the wider betting and gaming context.

Paper presented at the 10th International Conference on Gambling and Risk-Taking, Montreal, Canada.

Garner, C. (1995).

It could be YOUR child. The Sunday Mirror, June 6, 1995, 4-5.

Griffiths, M.D. (1991).

The psychobiology of the near miss in fruit machine gambling. Journal of Psychology, 125, 347-357.

Griffiths, M.D. (1993).

Fruit machine gambling: The importance of structural characteristics. Journal of Gambling Studies, 9, 133-152.

Griffiths, M.D. (1994).

The role of cognitive bias and skill in fruit machine gambling. British Journal of Psychology, 85, 351-369.

Griffiths, M.D. (1995a).

Adolescent Gambling. London: Routledge.

Griffiths, M.D. (1995b).

Scratch-card gambling: A potential addiction? Education and Health, 13, 17-20.

Griffiths, M.D. (1995c).

'Instant' gambling. [Letter]. The Times, April 19, 1995, 17.

\section{Griffiths, M.D. (1997).}

The National Lottery and scratchcards: A psychological perspective. The Psychologist: Bulletin of the British Psychological Society, 10, 23-26.

Griffiths, M.D. (1999).

The psychology of the near miss (revisited). British Journal of Psychology, 90, 441-445.

Griffiths, M.D. (2000).

Scratchcard gambling among adolescent males. Journal of Gambling Studies, 16, 79-91. 


\section{Home Office (1996).}

Casinos and Bingo Clubs: A Consultation Paper. London: Author.

Langer, E.J. (1975).

The illusion of control. Journal of Personality and Social Psychology, 32, 311-328.

Littler, S. (1996).

Regulation and the political perception of gambling. U.K. Forum on Young People and Gambling Newsletter, 19, 4-5.

\section{MacDonald, M. (1995).}

Shopkeepers break ban on child gamblers. The Independent, May 25, 1995, p. 3.

Moran, E. (1979).

An assessment of the Report of the Royal Commission on Gambling 1976-1978. British Journal of Addiction, 74, 3-9.

\section{Moran, E. (1987).}

Gambling among Schoolchildren: The Impact of the Fruit Machine. London: National Council on Gambling.

Moran, E. (1995).

Majority of secondary school children buy tickets. British Medical Journal, 311, 1225-1226.

Reid, R.L. (1986).

The psychology of the near miss. Journal of Gambling Behavior, 2, 32-39.

Royal Commission on Gambling. (1978).

Final Report: Royal Commission on Gambling. Cmnd 7200. London: HMSO.

Skinner, B.F. (1953).

Science and Human Behavior. New York: Free Press.

Wagenaar, W.A. (1988).

Paradoxes of Gambling Behavior. London: Erlbaum.

Wood, R.T.A. \& Griffiths, M.D. (1998).

The acquisition, development and maintenance of lottery and 
scratchcard gambling in adolescence. Journal of Adolescence, 21, 265-273.

This Opinion article was not peer-reviewed.

Submitted: March 18, 2002

Accepted: August 2, 2002

For correspondance:

Mark Griffiths, PhD

Department of Social Sciences

Nottingham Trent University

Nottingham, United Kingdom

Fax: 01159486826

Telephone: 01159418418 ext. 5502

E-mail: mark.griffiths@ntu.ac.uk

Mark Griffiths, PhD, is a professor of gambling studies at Nottingham Trent University, and is internationally known for his research on gambling and gaming addictions. In 1994, he was the first recipient of the John Rosecrance Research Prize for "outstanding scholarly contributions to the field of gambling research." He has published over 100 refereed research papers, numerous book chapters and over 250 other articles. His current interests are technological addictions, especially computer games and the Internet.

\section{Issue 7 -December 2002}

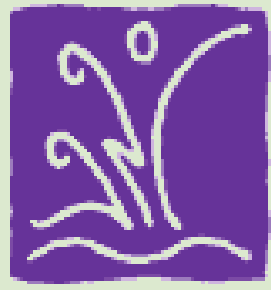

Centre

for Addiction and Mental Health

Centre de

toxicomanie et

de santé mentale 
intro | feature | opinion | research | service profile | first person accounts | reviews | letters | archive | submissions | subscribe | links

Copyright ( ) 1999-2002 The Centre for Addiction and Mental Health

Please note that these text links will always take you to articles from the current issue of eGambling. Use the navigation bar at the top left of the page to move around within back issues.

Editorial Contact: phil lange@camh.net

Subscribe to our automated announcement list: gamble-on@lists.camh.net

Unsubscribe: gamble-off@lists.camh.net 